\title{
Curriculum Vitae Hengki Wijaya
}

\author{
Hengki Wijaya \\ https://orcid.org/0000-0001-5063-9273
}

Biblical And Ethics Researcher, Head of Researching And Publishing Sekolah Tinggi Filsafat Theologia Jaffray, Lecture od Sekolah Tinggi Filsafat Theologia Jaffray

Websites

ResearcherID: N-5860-2015

Biography

My name is Hengki Wijaya. After graduated from Hasanuddin University in 2004 and continued my study at Sekolah Tinggi Filsafat Theologia Jaffray And finished in 2015 and be Master of Theology (M.Th). Now I still work at Researching and publishing STFT Jaffray. Now I am studying at Education science in mayor Model of learning development at Makassar State University was begin 2017 until now.

Sekolah Tinggi Filsafat Jaffray Makassar: Makassar, Sulawesi, ID

2012-12-12 to present | LPP STFT Jaffray (Researching And Publishing Organization)

Employment

Education and qualifications

Universitas Negeri Makassar: Makassar, South Sulawesi, ID

2017-08-07 to present | Cand. Dr (Education Science)

Education

Publication Works

The Role of Public Sphere according to Jurgen Habermas's perspective for multicultural societies in the Indonesian Context

DOI: $10.31219 /$ osf.io/d3th8

\section{Kepemimpinan Para Rasul dan Relevansinya Bagi Pemimpin Gereja di Era}

Revolusi Industri 4.0

DOI: $10.31219 /$ osf.io/7b65k

Optimalisasi Superego dalam Teori Psikoanalisis Sigmund Freud untuk

Pendidikan Karakter. DOI: 10.31219/osf.io/zmt6y. Tulisan yang berkolaborasi dengan I Putu Ayub Darmawan ${ }^{1}$ yang menjelaskan bagaimana superego memiliki kemampuan untuk

${ }^{1}$ Hengki Wijaya and I Putu Ayub Darmawan, “Optimalisasi Superego Dalam Teori Psikoanalisis Sigmund Freud Untuk Pendidikan Karakter” (Proceedings Seminar Nasional : merajut keragaman untuk 
meminimalkan potensi Id menjadi ego dengan meningkatkan nilai-nilai karakter pada anak usia dini.

Enhancing Students' Motivation to Learn Arabic Through Method of Muhadharah DOI: 10.31219/osf.io/34zta Bentuk kolaborasi dengan Nurmadiah, Sitti Sakinah (Universitas Indonesia Timur) dan Helaluddin (UIN Maulana Hasanuddin Banten).

The Intercultural Competence in Education Era 4.0: A Learning Strategy for Students of Elementary School in Indonesia. DOI: 10.31219/osf.io/e92zs. Kolaborasi dengan Harmelia Tulak, Susanna V. N. Rante (UKI Toraja), Nurmadiah, dan Helaluddin. ${ }^{2}$

Tilikan Politik dan Hak Asasi Manusia di Era Globalisasi DOI: 10.31219/osf.io/u5rg7

Lembar Kegiatan Anak Di Sentra Bahan Alam Berdasarkan Tematik DOI: 10.31219/osf.io/kdjer Dengan penulis utama St. Maria Ulfah (Kepala Sekolah TK).

Peran Gereja Masa Kini Menyikapi Teologi Pembebasan Gutiérrez. BIA': Jurnal Teologi dan Pendidikan Kristen Kontekstual

DOI: $10.34307 /$ b.v2i1.69

Konsep Bermegah (Boasting) dalam Surat Roma dan Implikasinya Bagi Gereja Masa KiniFIDEI: Jurnal Teologi Sistematika dan Praktika

DOI: $10.34081 /$ fidei.v2i1.24

Source:Crossref

Cergam Karakter Semangat Kebangsaan dan Toleransi untuk Anak Usia Dini 2019-05-06 | other

DOI: 10.31219/osf.io/rs9kn. Dengan penulis utama St. Maria Ulfah (Kepala Sekolah TK). ${ }^{3}$

Cerita Bergambar Karakter Tanggung Jawab dan cinta tanah air. Dengan penulis Utama Umrati. $^{4}$

2019-05-06 | other

DOI: 10.31219/osf.io/sjhxw

Source:Crossref

Fondasi Psikologis

2019-05-06 | other

mencapai kesejahteraan psikologis dalam konteks masyarakat 5.0 : Hotel Grand Wahid Salatiga, 2 Agustus 2019, Salatiga: Satya Wacana University Press, 2019).

${ }^{2}$ Harmelia Tulak et al., "The Intercultural Competence in Education Era 4.0: A Learning Strategy for Students of Elementary School in Indonesia," in Proceedings of the Proceedings of the 1st International Conference of Science and Technology in Elementary Education, ICSTEE 2019, 14 September, Makassar, South Sulawesi, Indonesia (Proceedings of the 1st International Conference of Science and Technology in Elementary Education, ICSTEE 2019, 14 September, Makassar, South Sulawesi, Indonesia, Makassar, Indonesia: EAI, 2019), https://doi.org/10.4108/eai.14-9-2019.2289961.

${ }^{3}$ St. Maria Ulfah and Hengki Wijaya, Cergam Karakter Semangat Kebangsaan Dan Toleransi Untuk. Anak. Usia Dini (Makassar: Sekolah Tinggi Theologia Jaffray Makassar, 2019).

${ }^{4}$ Umrati Umrati and Hengki Wijaya, Cerita Bergambar Karakter Tanggung Jawab Dan Cinta Tanah Air (Makassar: Sekolah Tinggi Theologia Jaffray Makassar, 2019). 
DOI: 10.31219/osf.io/46w9h

Prinsip-prinsip Etika Mengajar Pendidikan Agama Kristen Berdasarkan Alkitab. DOI: 10.31219/osf.io/2ncq3. Tulisan yang mengupas tentang etika mengajar dari perspektif Alkitab baik Perjanjian Lama maupun Perjanjian Baru.

Analisis Kebutuhan Karakter Mahasiswa Sekolah Tinggi Filsafat Jaffray Makassar untuk Pengembangan Model Pembelajaran Mata Kuliah Psikologi Umum. DOI:

10.31219/osf.io/4f8tz

Tulisan yang mengukur secara kualitatif melalui Focus Grup Discussion ${ }^{5}$ untuk melihat analisis kebutuhan mahasiswa untuk pengembangan model pembelajaran.

Implikasi Alkitab, Perundang-undangan, dan Budaya Lokal dalam Penguatan Pendidikan Karakter di Tri Pusat Pendidikan

2019-04-12 | other

DOI: $10.31219 /$ osf.io/eg45v

KEWIRAUSAHAAN NAMEKO (NASI MERAH KOTAK-KOTAK) DALAM MENGGIATKAN PANGAN LOKAL YANG SEHAT

2019-04-02 | other

DOI: $10.31219 /$ osf.io/vzd48

Tulisan mata kuliah Entrepreneurship untuk menggiatkan pangan local yang sehat.

Berkolaborasi dengan Tuflikha Primi Putri. ${ }^{6}$

PENGEMBANGAN KOMPETENSI PENDIDIK DI PERGURUAN TINGGI

DALAM MENYONSONG ERA REVOLUSI INDUSTRI 4.0

2019-04-02 | other

DOI: $10.31219 /$ osf.io/3mbs4

Pengembangan Model Pembelajaran Pendidikan Karakter Berbasis Media Sosial

DOI: 10.31219/osf.io/g68fs. Prosiding Seminar Nasional di UKI Toraja dengan penulis Hengki Wijaya dan Harmelia Tulak.

Pengembangan Model Pembelajaran Kooperatif Tipe STAD Berbasis Media Sosial. Jurnal Jaffray

2018-10-06 | journal-article

DOI: $10.25278 /$ jj71.v16i2.302

Part of ISSN: $2407-4047$

Ethics perspective and regulation of plagiarism in Higher Education

DOI: $10.33750 /$ ijhi.v1i1.4

Analisis Data Kualitatif Model Spradley (Etnografi)

2018 | other

\footnotetext{
${ }^{5}$ Hengki Wijaya and Helaluddin Helaluddin, Analisis Data Kualitatif Sebuah Tinjauan Teori \& Praktik (Makassar: Sekolah Tinggi Theologia Jaffray Makassar, 2019).

${ }^{6}$ Hengki Wijaya and Tuflikha P. Putri, "KEWIRAUSAHAAN NAMEKO (NASI MERAH

KOTAK-KOTAK) DALAM MENGGIATKAN PANGAN LOKAL YANG SEHAT” (Prosiding Seminar Nasional Pangan, Teknologi, dan Entrepreneurship, Makassar, Indonesia: Universitas Fajar Makassar, 2019), https://osf.io/vzd48.
} 
Belajar Membaca dan Menulis Untuk TK dan Kelas 1 SD

2018 | other Tugas mata kuliah model-model pembelajaran Berpikir induktif yang menghasil buku menulis permulaan untuk anak TK dan SD Kelas $1 .^{7}$

Hakikat Pendidikan Karakter

2018 | other

SOURCE-WORK-ID:

BASE:f8c86673495c095e80ec3d006000c18045a03a8fd556edc2a364cb68f88284a6

Tulisan mata kuliah yang berkolaborasi dengan teman sebaya Helaluddin. ${ }^{8}$

Implikasi Alkitab, Perundang-undangan, dan Budaya Lokal dalam Penguatan Pendidikan Karakter di Tri Pusat Pendidikan

2018 | other

SOURCE-WORK-ID:

BASE:025b3263e976b2b72a74743c1072189cd293b142f6352c553f70290b36e27bf1

Khotbah untuk Pendidikan Warga Jemaat

2018 | other

SOURCE-WORK-ID:

BASE:276e22e0a111494bde3142df6073aabef3dcad2d5911443a45d63443bcd49341

Pencegahan Plagiarisme dengan Anti-Plagiarism Software dan Reference Management Tools sebagai Terobosan Inovasi Pendidikan dalam Publikasi Karya Ilmiah ${ }^{9}$

2018 | other

SOURCE-WORK-ID:

BASE:9a0ad1352e3d2f9cb61dfe3d0e8a70354fdde61f25e9bf7cb064aa0323411431

Pendidikan Neurosains Dan Implikasinya Dalam Pendidikan Masa Kini ${ }^{10}$

2018 | other

SOURCE-WORK-ID:

BASE:5964cfa0818ba779206bcee2a98fe6db8742cc9c635e6155aef01 ee4109d2c8f

Penerapan Model Pembelajaran Cooperative Learning Tipe Think Pair Share Pada Materi LIistrik Dinamis Untuk Meningkatkan Hasil Belajar Siswa Kelas XI TKR1 SMK Negeri 2 TarakanJurnal Ilmu Pendidikan Fisika (JIPF)

2018 | journal-article

DOI: $10.26737 /$ jipf.v3i2.452

Peranan Teori Pendidikan dalam Mengatasi Anak Putus Sekolah Di Indonesia

\footnotetext{
${ }^{7}$ Hengki Wijaya and Helaluddin Helaluddin, “Hakikat Pendidikan Karakter,” 2018, https://repository.sttjaffray.ac.id/id/publications/269450/hakikat-pendidikan-karakter.

${ }^{8}$ Wijaya and Helaluddin.

${ }^{9}$ Hengki Wijaya, "Pencegahan Plagiarisme Dengan Anti-Plagiarism Software Dan Reference Management Tools Sebagai Terobosan Inovasi Pendidikan Dalam Publikasi Karya Ilmiah,” 2018, https:/ / repository.sttjaffray.ac.id/media/269000-pencegahan-plagiarisme-dengan-anti-plagi-4be399ee.pdf.

${ }^{10}$ Hengki Wijaya, "Pendidikan Neurosains Dan Implikasinya Dalam Pendidikan Masa Kini," 2018, https:/ / repository.sttjaffray.ac.id/media/269017-pendidikan-neurosains-dan-implikasinya-d-5854b17f.pdf.
} 
2018 | other

SOURCE-WORK-ID:

BASE:c8520a113e67e78ebb50407621dec7e25c82a199a4b6b4ed4f5dba0175b521e7

Ringkasan dan Ulasan Buku Analisis Data Penelitian Kualitatif (Prof. Burhan Bungin). ${ }^{11}$

2018 | other

SOURCE-WORK-ID:

BASE:53827b673e1099cb38ac5721dde16befb0237ecdd7f1f761b64beb556e95aa4c

Ringkasan Terjemahan Character Building: Sebuah Panduan untuk Orang Tua dan Guru (David Isaacs). ${ }^{12}$

2018 | other

SOURCE-WORK-ID:

BASE:6b41573edfbe661f88794f5529dec91c7eb837a048cdf3ae72be0541ddb150f3

Tinjauan Biblika Tentang Etika Kerajaan Allah Berdasarkan Injil Matius 5:3-12 dan Implementasinya Bagi Spiritualitas Gereja Masa Kini. ${ }^{13}$

2018 | other

SOURCE-WORK-ID:

BASE:1d4bf225354bbb1e91806842c4d1d5b1c44dbc36d9b42965ad18b3b7c59f292f

Ulasan Artikel Jurnal Pengembangan Kurikulum (Curriculum Development). ${ }^{14}$

2018 | other

SOURCE-WORK-ID:

BASE:53ff1e4a95d252a445641b49a3dd98fb0c586554d71017327804e1d8d4fa24a6

Hubungan Motivasi Belajar Ekstrinsik Terhadap Hasil Belajar Psikomotorik Pada Mata Pelajaran Agama Kristen Kelas V Di SD Zion MakassarJurnal Jaffray

2017-09 | journal-article

DOI: $10.25278 /$ jj $71 . v 15 i 2.262$

Part of ISSN: $2407-4047$

\footnotetext{
${ }^{11}$ Hengki Wijaya, "Ringkasan Dan Ulasan Buku Analisis Data Penelitian Kualitatif (Prof. Burhan Bungin)," 2018, https://repository.sttjaffray.ac.id/id/publications/269013/ringkasan-dan-ulasan-buku-analisisdata-penelitian-kualitatif-prof-burhan-bungin.

12 Hengki Wijaya, "Ringkasan Terjemahan Character Building: Sebuah Panduan Untuk Orang Tua Dan Guru (David Isaacs)," 2018.

${ }^{13}$ Hengki Wijaya, "Tinjauan Biblika Tentang Etika Kerajaan Allah Berdasarkan Injil Matius 5: 3-12 Dan Implementasinya Bagi Spiritualitas Gereja Masa Kini," 2018, https://www.researchgate.net/profile/Hengki_Wijaya3/publication/325961103_Tinjauan_Biblika_Tenta ng_Etika_Kerajaan_Allah_Berdasarkan_Injil_Matius_53-

12_Dan_Implementasinya_Bagi_Spiritualitas_Gereja_Masa_Kini/data/5b2fd61e0f7e9b0df5c6d84a/Tinja uan-Biblika-Tentang-Etika-Kerajaan-Allah.pdf.

${ }^{14}$ Hengki Wijaya, "Ulasan Artikel Jurnal Pengembangan Kurikulum (Curriculum Development)," 2018, https://repository.sttjaffray.ac.id/id/publications/269014/ulasan-artikel-jurnal-pengembangankurikulum-curriculum-development.
} 
Ulasan Buku: Whatever Happened To Worship A Call To True Worship..$^{15}$ Jurnal Jaffray 2017-03 | journal-article

DOI: $10.25278 /$ jj71.v15i1.241

Part of ISSN: $2407-4047$

Misi Dan Pelayanan Sosial: Manakah yang lebih Penting?

2017 | other

SOURCE-WORK-ID:

BASE:7367aacd30493f53f313e013fcbedafca8dd813e850fd1d187a1ec4b9ee02402

Source:Hengki WijayaviaBASE - Bielefeld Academic Search Engine

Proposal Reuni Akbar 85 Tahun Sekolah Tinggi Theologia Jaffray

2017 | other

SOURCE-WORK-ID:

BASE:fcf9aa1d1ec0074cb6709a42051e432c3dae633eaba882a8c88eb5ce21abf3ee

DOI: 10.13140/RG.2.2.36428.41602

Pengenaan Manusia Baru Di Dalam Kristus: Natur, Proses, Dan Fakta Serta Implikasi Teologis Dan PraktisnyaJurnal Jaffray

2016-03 | journal-article

DOI: $10.25278 /$ ji.v14i1.194.109-130

Part of ISSN: $1829-9474$

Pengenaan Manusia Baru Di Dalam Kristus: Natur, Proses, Dan Fakta Serta Implikasi Teologis Dan PraktisnyaJurnal Jaffray

2016-03 | journal-article

DOI: $10.25278 /$ jj $71 . v 14 i 1.194$

Part of ISSN: $2407-4047$

Metodologi Penelitian Pendidikan Teologi

2016 | other

Pendekatan Etika Kristen Dalam Pencegahan dan Penanggulangan Plagiarisme Akademik Dalam Mendukung Gerakan Anti Plagiarisme Di Perguruan Tinggi

2016 | other

SOURCE-WORK-ID:

BASE:81 fff08aa2ba245781b940bdc3834807a43359be1d1d781037aae1aa8e224acc

Pengenaan Manusia Baru Di Dalam Kristus: Natur, Proses, Dan Fakta Serta Implikasi Teologis Dan Praktisnya

2016 | journal-article

SOURCE-WORK-ID:

BASE:649d4ababdd646bb49ef165f9ad1d396300baf2e0541b733de6ac76f239cd412

Source:Hengki WijayaviaBASE - Bielefeld Academic Search Engine

${ }^{15}$ Hengki Wijaya, "Ulasan Buku: Whatever Happened To Worship A Call To True Worship," Jurnal Jaffray 15, no. 1 (March 19, 2017): 148, https://doi.org/10.25278/jj71.v15i1.241. 
Plagiarisme dalam Penelitian

2016 | other

SOURCE-WORK-ID:

BASE:79c55aa3ced143de219947039401258a954db03211b95ca02326954edbaa38dc

Source:Hengki WijayaviaBASE - Bielefeld Academic Search Engine

Pengajaran Tentang Panggilan Berdasarkan Kitab YunusProsiding Seminar Teologi Kitab Yunus

2015-09-15 | book-chapter

Kajian Teologis Tentang Penyembahan Berdasarkan Injil Yohanes 4:24Jurnal Jaffray 2015-03 | journal-article

DOI: $10.25278 /$ jij $71 . v 13 i 1.112$

Part of ISSN: 2407-4047

Source:Hengki WijayaviaCrossref Metadata Search

Analisis Dampak Pemanfaatan Internet Terhadap Indeks Prestasi Belajar Mahasiswa Sekolah Tinggi Theologia Jaffray Makassar

2015 | other

SOURCE-WORK-ID:

BASE:3f8e9075ebcc8934351df9219c50eddd776596e5c2568f77cef4b4f83da7e175

DOI: $10.13140 /$ RG.2.1.2757.5768

Source:Hengki WijayaviaBASE - Bielefeld Academic Search Engine

Etika Bisnis

2015 | other

SOURCE-WORK-ID:

BASE:5f9006d0783dca6a10e0a3621d26b19ab189d384d199bda15e685fc08d7af920

DOI: $10.13140 /$ RG.2.1.2064.4560

Source:Hengki WijayaviaBASE - Bielefeld Academic Search Engine

Faktor-Faktor Penentu Hegemoni Islam Masa Nabi Muhammad SAW

2015 | other

SOURCE-WORK-ID:

BASE:44ca6e2d2e4ca36c6bb5ae6dfed19902a2e6e06e56249f3fb4f87e65a83e965a

DOI: $10.13140 /$ RG.2.1.1901.2563

KAJIAN PENGGUNAAN NIRA AREN SEBAGAI SUBSTRAT PEMBUATAN RAGI ROTI (Saccharomyces cerevisiae)

2015 | other

Kemiskinan dan Kelaparan: Berbagai Pandangan dengan Perspektif yang Berbeda

2015 | other

SOURCE-WORK-ID:

BASE:405ea574e80f179cbab5b0cbcaf9c8d4657a749452df5ec4c63ea93888db5cb1

Keunggulan Integritas Generasi Muda Dalam Mewujudkan Kepemimpinan Rohani Yang BertanggungjawabResearchgate.net

2015 | other 
KEUNGGULAN INTEGRITAS GENERASI MUDA DALAM MEWUJUDKAN KEPEMIMPINAN ROHANI YANG BERTANGGUNGJAWAB

2015 | other

SOURCE-WORK-ID:

BASE:7aeb103355aa05832c7f72fbd29464f4cd17c9465cd69bc404ddd729ea7cb3cb DOI: 10.13140/RG.2.1.4264.9048

Kumpulan Khotbah Setahun Sebagai Upaya Pembinaan Jemaat

2015 | other

SOURCE-WORK-ID:

BASE:fd68f16c867aaa36f8f6250b3d03b9436b75573b1f69746ad1b02eedfebe117e

DOI: 10.13140/RG.2.1.1409.0968

Source:Hengki WijayaviaBASE - Bielefeld Academic Search Engine

Laporan Pertanggungjawaban Kegiatan Sola Scriptura 2015

2015 | report

SOURCE-WORK-ID:

BASE:8f92c70043ab8a7a390e61bd3479563a2207992ad0ef69f933b15858ffec4e6e

DOI: 10.13140/RG.2.2.11183.94883

Source:Hengki WijayaviaBASE - Bielefeld Academic Search Engine

Misi dan Pelayanan Sosial: Manakah yang lebih Penting?

2015 | other

SOURCE-WORK-ID:

BASE:faeb69f7d73c89b10769eb4258a7abe47c706fac8654c397c6ed063ad9f62e5f

DOI: $10.13140 /$ RG.2.1.4685.8961

Pengajaran Tentang Panggilan Berdasarkan Kitab Yunus

2015 | other

SOURCE-WORK-ID:

BASE:6b19fd8766b69d885464c28977e7152be1bbf111492956513a2108a3919b6adf

PRINSIP-PRINSIP PERTUMBUHAN GEREJA BERDASARKAN KITAB KISAH PARA RASUL

2019 | other

SOURCE-WORK-ID:

BASE:cc334c2a8cad66e34615df2f85ba403d455bb4b9f9ed09e9669aaf9f14964345

DOI: $10.13140 /$ RG.2.1.3113.0324

PRINSIP-PRINSIP PERTUMBUHAN GEREJA BERDASARKAN KITAB KISAH

PARA RASUL

2015 | other

Spiritualitas Kerajaan Allah: Khotbah Yesus di Bukit dan Implikasinya bagi Kehidupan Kristen

2015 | other

SOURCE-WORK-ID:

BASE:fed66c85e1b9e92f3af1e55912f424a82b61f842e0914cbe3009fcd467310e34 
Analisis Biblika Mengenai Penanggalan Manusia Lama dan Pengenaan Manusia Baru Berdasarkan Perspektif Surat Efesus 4:17-32

2014 | other

SOURCE-WORK-ID:

BASE:71367842a0cc2a1016e99803efe90c01e1f747b30461359d56e05180ff3f206a

Dasar Teologi Yang Teguh: Panduan Teologi Sistematika di Perguruan Tinggi 2013 | other

Menghormati Kekudusan Allah (2 Samuel 6:1-23) Khotbah Narasi Orang Pertama Jamak 2013 | other SOURCE-WORK-ID:

BASE:64d68aa6d8cc96126ebae23e1c06b7cfa6f6257aa08c8fdc27d756fe376110c5

Panggilan Pelayanan berdasarkan Perspektif Kitab Yunus

2013 | conference-paper

SOURCE-WORK-ID:

BASE:0b29bb91409ad76752310a42ae211e9592c9fa73147243fd07066ed8932d9c5c

DOI: 10.13140/RG.2.2.23798.40003

Source:Hengki WijayaviaBASE - Bielefeld Academic Search Engine

Mengapa Allah Memakai Dwight Lyman Moody? Kisah Hidup Seorang Pelayan Sekolah MingguJurnal Jaffray. ${ }^{16}$

2012-10-01 | journal-article

DOI: $10.25278 /$ jj $71 . v 10 i 2.52$

Part of ISSN: $2407-4047$

Apakah Jodoh adalah Pilihan Tuhan atau Pilihan Sendiri?

2012 | conference-paper

SOURCE-WORK-ID:

BASE:fb22bf14aa9874d4b762d1df9de62917d557ebf74aeddddcac302a7321df5b65

DOI: 10.13140/RG.2.2.23169.25440

Evaluasi Kritis Terhadap Teologi Sukses

2012 | other

SOURCE-WORK-ID:

BASE:93ab4ffe1797ed6ad7d98fd5191f11a58d884835e90130cfa8d1311e675a2c02

Fondasi Psikologis dalam Pendidikan Jemaat

2012 | conference-paper

SOURCE-WORK-ID:

BASE:ba15ca76e3fb1a1df8783aeae51d3496d6ec7538d5aa227558498616e6e411e5

DOI: $10.13140 /$ RG.2.2.13102.92486

${ }^{16}$ Hengki Wijaya, "Mengapa Allah Memakai Dwight Lyman Moody? Kisah Hidup Seorang Pelayan Sekolah Minggu," Jurnal Jaffray 10, no. 2 (October 1, 2012): 180, https://doi.org/10.25278/jj71.v10i2.52. 
Keintiman dengan TUHAN

2012 | conference-paper

SOURCE-WORK-ID:

BASE:ca8d0f035a1eedf34b4feb80b64a958a31 e5bbd5b186bf1a268b85e5a669ba8e DOI: $10.13140 /$ RG.2.2.33235.58403

Source:Hengki WijayaviaBASE - Bielefeld Academic Search Engine

Pandangan-pandangan tentang Kemiskinan dan Kelaparan

2012 | conference-paper

SOURCE-WORK-ID:

BASE:e618aa797504a6c4d0242233f23026ef09e6e2c11a6fca29a5992b857988eaab

DOI: 10.13140/RG.2.2.21491.53281

Analisis Biblika Terhadap Konsep Teologi Pembebasan Di Dalam Kekristenan 2011 | other

SOURCE-WORK-ID:

BASE:682f665aeb7f3a3341ac688d399e781db6e7e59d6fbe8dc4fee6baca23bda5ef

Eksposisi Gambar Allah Menurut Penciptaan Manusia Berdasarkan Kejadian 1:26-28

2011 | other

SOURCE-WORK-ID:

BASE:a473e42c6d55acd79ab5a1dbcc4c28fbf5806951a3e57e6e0436171c99d107b4

Kajian Penggunaan Nira Aren Sebagai Substrat Pembuatan Ragi Roti (Saccharomyces cerevisiae)

2004 | other

SOURCE-WORK-ID:

BASE:96941b2921f3cc1c4387757c204dae6cc3bd438a49c58c87a7d012f1f22ae54c

Source:Hengki WijayaviaBASE - Bielefeld Academic Search Engine

\section{References}

Tulak, Harmelia, Hengki Wijaya, Susanna N. Rante, Nurmadiah Nurmadiah, and Helaluddin Helaluddin. "The Intercultural Competence in Education Era 4.0: A Learning Strategy for Students of Elementary School in Indonesia." In Proceedings of the Proceedings of the 1st International Conference of Science and Technology in Elementary Education, ICSTEE 2019, 14 September, Makassar, South Sulawesi, Indonesia. Makassar, Indonesia: EAI, 2019. https://doi.org/10.4108/eai.14-9-2019.2289961.

Ulfah, St. Maria, and Hengki Wijaya. Cergam Karakter Semangat Kebangsaan Dan Toleransi

Untuk Anak Usia Dini. Makassar: Sekolah Tinggi Theologia Jaffray Makassar, 2019.

Umrati, Umrati, and Hengki Wijaya. Cerita Bergambar Karakter Tanggung Jawab Dan Cinta Tanah Air. Makassar: Sekolah Tinggi Theologia Jaffray Makassar, 2019.

Wijaya, Hengki. "Mengapa Allah Memakai Dwight Lyman Moody? Kisah Hidup Seorang Pelayan Sekolah Minggu." Jurnal Jaffray 10, no. 2 (October 1, 2012): 180. https://doi.org/10.25278/jj71.v10i2.52.

Wijaya, Hengki. "Pencegahan Plagiarisme Dengan Anti-Plagiarism Software Dan Reference Management Tools Sebagai Terobosan Inovasi Pendidikan Dalam Publikasi Karya 
Ilmiah,” 2018. https://repository.sttjaffray.ac.id/media/269000-pencegahanplagiarisme-dengan-anti-plagi-4be399ee.pdf.

Wijaya, Hengki. "Pendidikan Neurosains Dan Implikasinya Dalam Pendidikan Masa Kini," 2018. https://repository.sttjaffray.ac.id/media/269017-pendidikan-neurosains-danimplikasinya-d-5854b17f.pdf.

Wijaya, Hengki. "Ringkasan Dan Ulasan Buku Analisis Data Penelitian Kualitatif (Prof. Burhan Bungin)," 2018.

https://repository.sttjaffray.ac.id/id/publications/269013/ringkasan-dan-ulasanbuku-analisis-data-penelitian-kualitatif-prof-burhan-bungin.

Wijaya, Hengki. "Ringkasan Terjemahan Character Building: Sebuah Panduan Untuk Orang Tua Dan Guru (David Isaacs)," 2018.

Wijaya, Hengki. "Tinjauan Biblika Tentang Etika Kerajaan Allah Berdasarkan Injil Matius 5: 3-12 Dan Implementasinya Bagi Spiritualitas Gereja Masa Kini,” 2018. https://www.researchgate.net/profile/Hengki_Wijaya3/publication/325961103_Ti njauan_Biblika_Tentang_Etika_Kerajaan_Allah_Berdasarkan_Injil_Matius_5312_Dan_Implementasinya_Bagi_Spiritualitas_Gereja_Masa_Kini/data/5b2fd61e0f 7e9b0df5c6d84a/Tinjauan-Biblika-Tentang-Etika-Kerajaan-Allah.pdf.

Wijaya, Hengki. "Ulasan Artikel Jurnal Pengembangan Kurikulum (Curriculum Development)," 2018.

https://repository.sttjaffray.ac.id/id/publications/269014/ulasan-artikel-jurnalpengembangan-kurikulum-curriculum-development.

Wijaya, Hengki. "Ulasan Buku: Whatever Happened To Worship A Call To True Worship." Jurnal Jaffray 15, no. 1 (March 19, 2017): 148. https://doi.org/10.25278/jij1.v15i1.241.

Wijaya, Hengki, and I Putu Ayub Darmawan. "Optimalisasi Superego Dalam Teori Psikoanalisis Sigmund Freud Untuk Pendidikan Karakter.” Salatiga: Satya Wacana University Press, 2019.

Wijaya, Hengki, and Helaluddin Helaluddin. Analisis Data Kualitatif Sebuah Tinjauan Teori \& Praktik. Makassar: Sekolah Tinggi Theologia Jaffray Makassar, 2019.

Wijaya, Hengki. "Hakikat Pendidikan Karakter," 2018. https:// repository.sttjaffray.ac.id/id/publications/269450/hakikat-pendidikankarakter.

Wijaya, Hengki, and Tuflikha P. Putri. "KEWIRAUSAHAAN NAMEKO (NASI MERAH KOTAK-KOTAK) DALAM MENGGIATKAN PANGAN LOKAL YANG SEHAT.” Makassar, Indonesia: Universitas Fajar Makassar, 2019. https://osf.io/vzd48. 